\title{
Dapsone Alone Compared with Dapsone Plus Rifampicin in Short-term Therapy of Lepromatous Leprosy
}

\author{
R. H. GELBER, ${ }^{* \dagger}$ M. F. R. WATERS, J. M. H. PEARSON $\ddagger$ \\ Leprosy Research Unit, National Leprosy Control Center, \\ Sungei Buloh, Malaysia and ${ }^{*}$ Department of International Health \\ University of California, San Francisco, U.S.A. \\ R. J. W. REES \\ National Institute for Medical Research Mill Hill, London NW7 1 AA \\ and \\ A. C. McDOUGALL \\ Department of Human A natomy Oxford University, Oxford OXI 3QX, U.K.
}

\begin{abstract}
Previously untreated lepromatous leprosy patients were randomly allocated to treatment with either $100 \mathrm{mg}$ dapsone daily or $100 \mathrm{mg}$ dapsone and $600 \mathrm{mg}$ rifampicin daily for 6 months. Patients receiving rifampicin improved more rapidly, but by 6 months the regimens were equivalent. There was no difference in the incidence, severity, and time of onset of erythema nodosum leprosum (ENL) in the 2 groups. Skin smears and histological sections and mouse foot-pad inoculation of biopsy specimens from skin, peripheral nerve, skeletal muscle and dartos muscle demonstrated more rapid killing of Mycobacterium leprae in those on combination chemotherapy. In the patients treated only with dapsone, viable $M$. leprae were generally found after 3 months of therapy, and frequently even at 6 months. Even on the combined regimens, viable $M$. leprae were commonly detected at 3 months, but only occasionally at 6 months.
\end{abstract}

\section{Introduction}

Rees et al. (1970) reported that rifampicin was active against $M$. leprae infection of the mouse foot-pad and at the same time demonstrated in lepromatous leprosy patients that $600 \mathrm{mg}$ rifampicin daily by mouth killed organisms more rapidly than dapsone or any other antileprosy drug studied thus far. The evidence for the rapid bactericidal activity of rifampicin was extended by a series of reports from Shepard et al. (1972, 1974). Mouse inoculation of skin biopsy specimens from previously untreated lepromatous leprosy patients became negative 3 to 4 days

$\dagger$ Requests for reprints should be addressed to R. H. Gelber at his present address: United States Public Health Service Hospital, 15th Avenue and Lake Street, San Francisco, California 94118.

$\ddagger$ Present address: Medical Research Council Leprosy Project, P.O. Box 1005, Addis Ababa, Ethiopia.

Received for publication 14 June, 1977. 
after daily $600 \mathrm{mg}$ rifampicin or after a single dose of $1500 \mathrm{mg}$. In contrast, biopsy material from patients treated with daily dapsone on the average is not rendered non-infectious for mice for 3 months (Shepard et al., 1968).

In recent years the dual processes of bacterial resistance and persistence have emphasized the need for combination chemotherapy of lepromatous leprosy.

Sulphone resistance was first proven by Pettit and Rees (1964) in Malaysia in 1964. Recently, the Malaysian experience with the first 100 proven cases of dapsone resistance has been published (Pearson et al., 1975). Both irregularity of therapy and low sulphone dosage appear to predispose lepromatous leprosy patients to dapsone-resistant relapse. Estimates of the risks of developing dapsone resistance in lepromatous leprosy have ranged from $2.5 \%$ in Malaysia (Pearson et al., 1975), 6.8\% in Costa Rica (Peters et al., 1976) and something like $40 \%$ in Ethiopia (Pearson, 1975; Pearson et al., 1977). As in the chemotherapy of tuberculosis, the obvious remedy is treatment with a combination of agents.

Waters et al. (1974) reported the results of mouse foot-pad inoculation of skin, skeletal muscle, peripheral nerve and dartos muscle from 12 Malaysian lepromatous patients who had completed a minimum of 10 years of supervised dapsone therapy in full dosage. Ten of the 37 specimens and 7 of the 12 patients still harbored persisting viable $M$. leprae which when passaged to mice were shown to be fully sensitive to dapsone. Evidence that bacterial persistence might be a problem in the treatment of lepromatous leprosy also came from a study of the Karimui of Papua New Guinea in which 5 of 28 lepromatous patients were found to have solid-staining bacilli in their skin smears despite regular treatment with acedapsone for 3 to 5 years and expected blood sulphone levels (Russell et al., 1975). These results emphasize that monotherapy with dapsone is not sufficient treatment for lepromatous leprosy.

It appears inconsistent that viable $M$. leprae cannot be detected after a few months of dapsone or even a few days of rifampicin, but are regularly found af ter some years of dapsone therapy. This is most likely a methodological paradox. In the mouse foot-pad infection $5 \times 10^{3}$ are inoculated, and if more than 5 viables are present in the initial inoculum, these grow yielding $10^{6} \mathrm{M}$. leprae by 6 months. It is estimated that an untreated lepromatous leprosy patient harbors $10^{12}$ organisms in his body, of which $10^{10}$ to $10^{11}$ are viable. If initial antimicrobial therapy reduces the viables by $99.9 \%$ to $10^{7}$ to $10^{8}$ organisms, inocula of 5000 organisms may contain no viable bacilli. However, as dead organisms are preferentially cleared from the tissues, the proportion of viable organisms increases so that detection of $M$. leprae by mouse foot-pad inoculation again becomes possible.

As a first study of the efficacy of combined chemotherapy, we, therefore, initiated a short-term study of dapsone plus rifampicin therapy compared to dapsone alone in previously untreated patients with lepromatous leprosy.

\section{Patients and Methods}

Previously untreated patients who were clinically lepromatous and classified histologically as LL or LI by Ridley were hospitalized for the trial period at the Leprosy Research Unit, National Leprosy Control Center, Sungei Buloh, Malaysia, and randomly assigned to one of 2 treatment regimens. Six patients, 4 Chinese males, one Chinese female and one Malay male ingested $100 \mathrm{mg}$ dapsone and placebo resembling rifampicin daily for 6 months. Five patients, 2 Chinese males, 
2 Malay males and one Chinese female ingested $100 \mathrm{mg}$ dapsone and $600 \mathrm{mg}$ rifampicin daily for 6 months.

Patients were followed by clinical, histological and bacteriological criteria for the duration of the trial. Clinical response was assessed by the clinical investigators and by an independent experienced leprologist. Smears from the same 6 skin sites were taken prior to therapy, every 2 weeks for 6 weeks and at 3 , 4, 5 and 6 months for assessment of the bacteriological index (BI) and morphological index (MI). Biopsies were taken prior to therapy and at 3 and 6 months after the initiation of treatment from skin (S), peripheral nerve $(\mathrm{N})$, skeletal muscle (M) and, from the men, dartos muscle (D) for histological examination and mouse foot-pad inoculation. Each biopsied tissue was homogenized and inoculated into both hind foot-pads of 6 female CBA mice. Doses of up to $10^{4}$ acid-fast bacilli from the pretreatment biopsied tissues and up to $10^{5}$ acid-fast bacilli from the tissues biopsied after starting treatment, were inoculated into normal and thymectomized-irradiated mice respectively.

\section{Results}

There was a decrease in lepromatous infiltrate in all patients in the study. Patients treated with dapsone and rifampicin generally showed more rapid clinical improvement than those receiving only dapsone. In particular, patients receiving rifampicin were noted to have more rapid reduction of erythema of skin lesions, alleviation of nasal congestion and, where present, healing of primary lepromatous ulceration. However, at the completion of 6 months of therapy, no discernible difference between the 2 regimens was found. Four of the 6 patients receiving dapsone alone developed ENL during the course of the trial, in 3 instances the ENL was mild and in one moderate, while 4 of the 5 patients that also were treated with rifampicin had mild ENL. The addition of rifampicin did not result in earlier or more severe ENL.

The average BI and MI were derived by first averaging the results of the 6 skin smears from each patient at each time interval, and these in turn averaged for the 6 patients receiving dapsone alone and the 5 on the combined regimen. In those patients receiving dapsone alone, the average pretreatment BI was 4.55 and was still 4.47 after 6 months of therapy. On the other hand, the BI prior to therapy averaged 4.56 in those on the combined regimen but fell significantly $(P<0.01)$ to 4.06 after completion of the 6 month trial period. The results of the morphological indexes are presented in Table 1. The average MI prior to therapy in those receiving dapsone alone was 22.7 , which was not significantly different from the average MI of 23.8 found in those patients who subsequently received dapsone plus rifampicin. The MI fell more rapidly in those on the combination

TABLE 1

Average morphological index (MI)

\begin{tabular}{lccccccc}
\hline & Pretreatment & $\begin{array}{c}2 \\
\text { weeks }\end{array}$ & $\begin{array}{c}4 \\
\text { weeks }\end{array}$ & $\begin{array}{c}6 \\
\text { weeks }\end{array}$ & $\begin{array}{c}3 \\
\text { months }\end{array}$ & $\begin{array}{c}4.5 \\
\text { months }\end{array}$ & $\begin{array}{c}6 \\
\text { months }\end{array}$ \\
\hline $\begin{array}{l}\text { Dapsone } \\
\begin{array}{l}\text { Dapsone+ } \\
\text { rifampicin }\end{array}\end{array}$ & 22.7 & 19.5 & 16.2 & 7.9 & 3.1 & 0.5 & 0.2 \\
\hline
\end{tabular}


TABLE 2

Infectivity (viability) in the mouse of $\mathrm{M}$. leprae from skin (S), nerve (N), striated muscle (M) and dartos muscle (D) of patients treated with dapsone $100 \mathrm{mg}$ daily either alone or combined with rifampicin $600 \mathrm{mg}$ daily

\begin{tabular}{|c|c|c|c|c|c|c|c|c|c|c|c|c|}
\hline \multirow[t]{2}{*}{$\begin{array}{l}\text { Treatment } \\
\text { regimen }\end{array}$} & \multirow{2}{*}{$\begin{array}{l}\text { Duration of } \\
\text { treatment } \\
\text { (months) }\end{array}$} & \multicolumn{5}{|c|}{$\begin{array}{l}\text { Proportion of foot-pads } \\
\text { showing multiplication } \\
\text { (by biopsy site) }\end{array}$} & \multicolumn{5}{|c|}{$\begin{array}{l}\text { Proportion of sites yielding } \\
\text { positive foot-pads }\end{array}$} & \multirow{2}{*}{$\begin{array}{l}\text { Proportion of patients } \\
\text { yielding positive } \\
\text { foot-pads from at least } \\
\text { one tissue site }\end{array}$} \\
\hline & & $\mathrm{S}$ & $\mathrm{N}$ & M & D & Totals & $\mathrm{S}$ & $\mathrm{N}$ & M & $\mathrm{D}$ & Totals & \\
\hline \multirow[t]{2}{*}{ Dapsone } & \multirow[t]{2}{*}{3} & 22 & 15 & 9 & 5 & 51 & 5 & 3 & 2 & 1 & 11 & 5 \\
\hline & & 54 & 50 & $\overline{54}$ & 44 & 202 & 6 & 6 & 6 & 5 & $\frac{11}{23}$ & $\frac{2}{6}$ \\
\hline \multirow{2}{*}{$\begin{array}{l}\text { Dapsone+ } \\
\text { rifampicin }\end{array}$} & \multirow[t]{2}{*}{3} & 1 & 2 & 5 & 4 & 12 & 1 & 1 & 1 & 2 & 5 & 3 \\
\hline & & 52 & 50 & $\frac{\overline{48}}{48}$ & 38 & 188 & 5 & 5 & 5 & 4 & $\frac{\overline{19}}{19}$ & $\frac{2}{5}$ \\
\hline \multirow[t]{2}{*}{ Dapsone } & \multirow[t]{2}{*}{6} & 1 & 8 & 4 & 6 & 19 & 1 & 2 & 2 & 2 & 7 & 3 \\
\hline & & 53 & 52 & 48 & 46 & 199 & 6 & 6 & 6 & 5 & $\overline{23}$ & $\frac{5}{6}$ \\
\hline \multirow{2}{*}{$\begin{array}{l}\text { Dapsonet } \\
\text { rifampicin }\end{array}$} & \multirow[t]{2}{*}{6} & 1 & 0 & 1 & 0 & 2 & 1 & 0 & 1 & 0 & 2 & 1 \\
\hline & & $\frac{1}{40}$ & $\frac{v}{42}$ & 30 & $\frac{0}{40}$ & $\frac{2}{152}$ & 5 & $\frac{v}{5}$ & 4 & 4 & 18 & $\frac{1}{5}$ \\
\hline
\end{tabular}


regimen. The MI was found to be significantly lower in those receiving rifampicin plus dapsone than in those treated with dapsone alone at 2, 4 and 6 weeks, and at 3 months $(P<0.01$ at all these intervals). These results suggest that rifampicin plus dapsone kills $M$. leprae significantly more rapidly than does dapsone alone.

After the initial pretreatment biopsy, histological sections showed no solidstaining bacilli in any of the sampled tissues from those receiving combination chemotherapy except an occasional solid-staining organism from the skin of a single patient at 3 months. On the other hand, histological sections from patients receiving dapsone alone revealed solid-staining bacilli from at least one site in 4 of the 6 patients at 3 months and 3 of the 6 patients even at 6 months. Skin and nerve were the most common source of these solid-staining organisms.

In Table 2 are presented the results of the mouse foot-pad inoculations. At 3 months 5 of the 6 patients receiving dapsone alone and 3 of the 5 patients receiving dapsone plus rifampicin were found to harbor viable bacilli from at least one tissue site. Though not statistically significant, a greater percentage of tissues after 3 months of therapy contained viable $M$. leprae from patients receiving dapsone ( 11 of $23,48 \%$ ), compared to those from patients on combined therapy ( 5 of 19, 26\%). Of particular interest is that at 3 months, 5 of 6 skin biopsies contained $M$. leprae viable for mice from those receiving dapsone alone, while only one of 5 skin biopsies from those on the combined regimen harbored viable bacilli. A statistically highly significantly $(P<0.0001)$ greater number of total foot-pads showed multiplication at 3 months of therapy from those receiving dapsone alone $(51 / 202,25 \%)$ compared to those receiving rifampicin in addition $(12 / 188,6 \%)$. Skin and peripheral nerve particularly accounted for those differences $(P<0.01$ for each compared independently). At 6 months after the initiation of therapy 3 of 6 patients receiving only dapsone yielded $M$. leprae from at least one tissue site that grew in the mouse foot-pad, compared to only one of the 5 patients treated with dapsone plus rifampicin. From the patients receiving combined chemotherapy only 2 of $18(11 \%)$ tissues, skin and skeletal muscle from the same patient, showed multiplication of $M$. leprae in the foot-pads of mice. Though not statistically significantly different, 7 of $23(30 \%)$ sampled tissues from patients on dapsone alone contained M. leprae that grew in the mouse foot-pad. As at 90 days, a highly significantly $(P<0.0001)$ greater number of total foot-pads showed multiplication f rom tissue of patients on dapsone alone (19 of 199 , or $10 \%$ ) compared to those on the combined regimen ( 2 of 152 , or $1 \%)$. Nerve and dartos muscle particularly appear responsible for this difference.

\section{Discussion}

These studies resulted in clinical, histological and bacteriological evidence that dapsone plus rifampicin is more effective than dapsone alone in the therapy of patients with previously untreated lepromatous leprosy. Whether this combination merely kills organisms more rapidly and whether more prolonged dapsone therapy would result in equally efficacious results, albeit more slowly, remains for further trials. Certainly such combination chemotherapy should prevent future relapse with resistant organisms. Because of the expense of rifampicin for most developing countries where leprosy is a problem, finding the minimal amount of rifampicin necessary is most important. From the frequency of recovery of viable M. leprae in this study, it appears that 3 months and possibly even 6 months of daily therapy may not even be sufficient. This does not rule out the utility of 
rifampicin in some intermittent regimen. However, because of the potential for serious toxicity when rifampicin is given intermittently (Aquinas et al., 1972), such trials should be entertained with great caution.

One of the major goals in leprosy chemotherapy is to find sufficiently potent antimicrobial regimens to reduce the therapy for lepromatous leprosy from lifelong to a finite and practical period of time. Rees (1975) and Rees et al. (1976) recently reported a study of 28 dapsone-resistant lepromatous leprosy patients who had relapsed, that were subsequently treated with $600 \mathrm{mg}$ rifampicin daily and in most thiambutosine as well for 0.5 to 5 years. M. leprae were isolated from one or more of the 4 tissue sites sampled in 20 of these patients. All 11 of those patients treated from 2 to 5 years with daily rifampicin yielded $M$. leprae that multiplied in mice. Pessimistically, one might ask if lepromatous leprosy can ever be cured by chemotherapy alone. On the other hand, just as the duration necessary for the therapy of pulmonary tuberculosis has been significantly reduced by the use of regimens containing 2 or 3 bactericidal agents (Fox and Mitchison, 1975), might lepromatous leprosy be similarly responsive? Clearly, the search for new bactericidal drugs and regimens against $M$. leprae in experimental animals and man must continue to be pursued.

\section{Acknowledgements}

It is a pleasure to thank Dr D. S. Ridley of the Hospital for Tropical Diseases, London, for the histological classification of our leprosy patients and Dr M. K. Bhojwani for independent clinical assessment.

Dr Gelber was supported by the University of California International Center for Medical Research (UC ICMR) through research grant AI 10051 to the Department of International Health, School of Medicine, University of California, San Francisco, from the National Institute of Allergy and Infectious Disease, National Institutes of Health, U.S. Public Health Service. Dr Gelber also acknowledges the support of the Institute for Medical Research, Malaysia. The Leprosy Research Unit, Sungei Buloh, Malaysia, is jointly administered by the (British) Medical Research Council and the Malaysian Ministry of Health.

\section{References}

Aquinas, M., Alan, W. G. L., Horsfall, P. A. L., Jenkins, P. K., Wong, H.-Y., Girling, D., Tall, R. and Fox, W. (1972). Adverse reactions to daily and intermittent rifampicin regimens for pulmonary tuberculosis in Hong Kong. Br. med. J. i. 765.

Fox, W. and Mitchison, D. A. (1975). Short course chemotherapy for pulmonary tuberculosis. Am. Rev. resp. Dis. 3, 325.

Pearson, J. M. H. (1975). Proceedings of the Workshop on Leprosy Chemotherapy.

Pearson, J. M. H., Rees, R. J. W. and Waters, M. F. R. (1975). Sulphone resistance in leprosy. A review of one hundred proven clinical gases. Lancet $i i, 69$.

Pearson, J. M. H., Cap, J. A., Haile, G. S. and Rees, R. J. W. (1977). Drug-resistant leprosy and its implications for leprosy control programmes. Lepr. Rev. 48, 73.

Peters, J. H., Shepard, C. C., Gordon, G. R., Rojas, A. V. and Elizondo, D. S. (1976). The incidence of DDS resistance in lepromatous patients in Costa Rica; their metabolic disposition of DDS. Int. J. Lepr. 44, 143.

Pettit, J. H. S. and Rees, R. J. W. (1964). Studies on sulphone resistance in leprosy. An experimental and clinical study. Lancet ii, 673.

Rees, R. J. W. (1975). Rifampicin: the investigation of a bactericidal antileprosy drug. Lepr. Rev. 46, 121.

Rees, R. J. W., Pearson, J.M.H. and Waters, M.F. R. (1970). Experimental and clinical studies on rifampicin in treatment of leprosy. Brit. med. J. $i, 89$.

Rees, R. J.W., Waters, M. F. R., Pearson, J. M. H., Helmy, H. S. and Laing, A. B. C. (1976). Long-term treatment of dapsone-resistant leprosy with rifampicin: clinical and bacteriological studies. Int. J. Lepr. 44, 149. 
Russell, D. A., Shepard, C. C., McRae, D. H., Scott, G. C. and Vincin, D. R. (1975). Acedapsone (DADDS) treatment of leprosy in the Karimui of Papua New Guinea: status at six years. Am. J. trop. Med. Hyg. 24, 485.

Shepard, C. C., Levy, L. and Fasal, P. (1968). The death of Mycobacterium leprae during treatment with 4,4' dia minodiphenylsulf one (DDS). A m. J. trop. Med. Hyg. 17, 769.

Shepard, C. C., Levy, L. and Fasal, P. (1972). Rapid bactericidal effect of rifampin on Mycobacterium leprae. Am J. trop. Med. Hyg. 21,446.

Shepard, C. C., Levy, L. and Fasal, P. (1974). Further experience with the rapid bactericidal effect of rifampin on M. leprae. Am J. trop. Med. Hyg. 23, 1120.

Waters, M. F. R., Rees, R. J. W., McDougall, A. C. and Weddell, A. G. M. (1974). Ten years of dapsone in lepromatous leprosy: clinical bacteriological and histological assessment and the finding of viable leprosy bacilli. Lepr. Rev. 45, 288. 